\title{
DYNAMICS AND ANALYTICS OF PUBLIC ELECTRIC PASSENGER MINIBUS HEATING
}

\author{
Raimunds Selegovskis, Aigars Laizans, Janis Galins, Aivars Rubenis \\ Latvia University of Life Sciences and Technologies, Latvia \\ raimunds.selegovskis@1lu.lv, aigars.laizans@1lu.lv, janis.galins@1lu.lv, \\ aivars.rubenis@transfoelectric.com
}

\begin{abstract}
One of the problems with electric buses and minibuses is that the passenger compartment heating system with electric heaters consumes energy from electric accumulators, thereby reducing the driving distance. Various manufacturers and researchers have tried to address this problem by using a heating system that works on gasoline or diesel. It does not allow such a bus to be added to green vehicles because of fossil fuels producing emissions. Another solution is the use of heat pumps. However, since they consume electricity, it does not completely solve the problem. One of the solutions is to store the heat in heat batteries that are charged at the same time as electrical. The purpose of this study is to identify the dynamic model of the passenger compartment and find out analytic expressions for calculating the requirements for the autonomous heating system. On-thefield experiments were provided with the electric minibus to get data about heating and cooling dynamics, in order to determine analytic expressions. Electrical heater was placed in the passenger compartment, temperature sensors were placed at different points of compartment and outside, temperature and the heater power measurements were performed. A stabilized stationary regime characterizing the equality of incoming and outgoing heat flows was reached. The research showed that the time of inertia of the passenger minibus is 115 minutes, and the response to the heat energy was 2.0 degrees $\mathrm{C}$ per $1 \mathrm{~kW}$. The results of the studies shall be used to develop an electric minibus heating system using heat batteries.
\end{abstract}

Keywords: electric minibus, autonomous heating, temperature distribution, heat flow.

\section{Introduction}

A challenge for electric buses is to organize heating and cooling power to not decrease the driving range, but still provide sufficient thermal comfort for the driver and passengers.

For passenger electric vehicles (EV), the energy consumption due to the heating and cooling system can reduce the overall driving range by $40-60 \%$ under typical standard driving testing conditions [1].

For bus passenger compartment heating the following systems are usually used:

- electric heaters (PTC);

- heat pumps for heating and cooling;

- heaters on fuel using diesel or similar fuel (e.g. Webasto, Eberspächere.t.c).

Electrical heaters decrease the driving range using considerable energy from vehicle batteries. Using of fuels produces emissions and therefore the vehicle is not more the green energy vehicle. Heat pump consumes the electric power from the vehicle's electric accumulators.

The using of heat accumulation in special heat accumulators for electric bus heating by charging them simultaneously with electric batteries is one of the possible solutions.

The main aim of this investigation is to define the necessary conditions for the heat capacity of such heat accumulators that can provide heating of the passenger compartment during the route between charging points for city traffic passenger minibuses.

There are two temperature thresholds: the thermal sense and thermal comfort of passengers in the buses. During an autumn or spring day (outside temperature $+13.4 \pm 0.5{ }^{\circ} \mathrm{C}$, relative humidity $60 \pm 5.8 \%$ ) the temperature in the bus has to be of $+22.5 \pm 1.1^{\circ} \mathrm{C}$ that corresponds to a slightly warm feeling [2]. Thermal sense is related significantly to the bus temperature, clothing insulation and human age. Linear regression based on these parameters showed that the temperature in the bus corresponding to thermal comfort would be $20.9 \pm 0.6{ }^{\circ} \mathrm{C}$. $1.6^{\circ} \mathrm{C}$ lower bus temperature during the cool day probably would have led to less thermal discomfort and energy savings of electrical busses [2].

The Association of German Transport Companies recommends the bus inside air temperature in the range from 17 to $210 \mathrm{C}$ if the outside temperature is in the range -10 to $22{ }^{\circ} \mathrm{C}$ [3]. 
The HVAC system shall control the average passenger compartment temperature within a range between 18 and $27^{\circ} \mathrm{C}\left(65\right.$ and $\left.80^{\circ} \mathrm{F}\right)$, while maintaining the relative humidity to a value of $50 \%$ or less. The system shall maintain these conditions while subjected to any outside ambient temperatures within a range of $-12{ }^{\circ} \mathrm{C}$ to $35^{\circ} \mathrm{C}\left(10\right.$ to $\left.95^{\circ} \mathrm{F}\right)$ and at any ambient relative humidity levels between 5 and $50 \%$. When the bus is operated in outside ambient temperatures in the range of -23 to $-12{ }^{\circ} \mathrm{C}$ $\left(-10\right.$ to $\left.10^{\circ} \mathrm{F}\right)$, the interior temperature of the bus shall not fall below $13^{\circ} \mathrm{C}\left(55^{\circ} \mathrm{F}\right)$ [1].

A simple approach for evaluating the thermally comfortable environment is the equivalent temperature $\left(\mathrm{T}_{\text {eq }}\right)$ [4] that rates the average air temperature and radiant temperature [5]. But in cold seasons passengers wear warm clothes, therefore it is not necessary to provide temperatures inside the bus so high (no more $21^{\circ} \mathrm{C}$ ).

Table 1

Thermal comfort level [4]

\begin{tabular}{|c|c|}
\hline Equivalent temperature $\boldsymbol{T}_{e q},{ }^{\mathbf{0}} \mathbf{C}$ & Thermal comfort sensation \\
\hline$T_{e q}<18.5$ & Too cold, uncomfortable \\
\hline $18.5<T_{e q}<22$ & Cold, but comfortable \\
\hline $22<T_{e q}<24.5$ & Neutral \\
\hline $24.5<T_{e q}<2 ., 5$ & Hot, but comfortable \\
\hline $27.5<T_{e q}$ & Too hot, uncomfortable \\
\hline
\end{tabular}

In normal operation the energy requirements for heating consist of the regular heat transmission through walls, windows, etc., warming heat of the inflowing cold fresh air, exchange flow heating when the doors are opened at bus stops. The total amount of energy for heating directly depends on the ambient air temperature.

Electric vehicle mileage is limited because of its dependence on the battery and is reduced due to the use of battery power for heating in winter and air conditioning in summer. In particular, the capacity of lithium-ion batteries decreases as the temperature of the battery falls. At a temperature of $-25^{\circ} \mathrm{C}$, the capacity is decreased to $60 \%$ of that at $25^{\circ} \mathrm{C}$. The power for heating of a regular passenger bus is in the range from approximately $5 \mathrm{~kW}$ (outside temp $10^{\circ} \mathrm{C}$ ) to nearly $30 \mathrm{~kW}$ (outside temp $-20^{\circ} \mathrm{C}$ ) [6]. These values are valid for buses with 40 and more passenger seats.

The energy consumption to provide comfortable microclimate in the bus passenger compartment is affected by air infiltration of ambient air. The literature describes studies of additional options for reducing this energy consumption, such as using an air curtain that reduces the outdoor air infiltration in a bus at stops [7]. The mentioned investigations are performed for cooling, but probably it is possible to use this option also in winter time by combining air curtains and the bus heating system.

In our case, we have a passenger minibus with 18 seats for regular traffic in city route with fast charging sources in end terminals and some charging points in intermediate stops during the route. This minibus is provided to a regular passenger route in one of Latvia cities. Its dimensions and volume essentially differ from a regular big passenger bus. Therefore, it is necessary to establish the heat flow characteristic directly for such bus. The results can be taken into account for another similar passenger minibus.

The aims of the investigations were to determine the necessary data for heating power choice to maintain comfortable temperature regimes in the passenger cabin, to determine the heat flow and its distribution, as well as heating and cooling dynamics.

\section{Theoretical description of processes}

For the investigation of heating and cooling, it is possible to consider the minibus as a unitary body to which heat is supplied, which then returns it to the environment. The non-stationary heating process is described with the balance equation of the supplied power $P$ and heat:

$$
Q_{a}+Q_{v}=P,
$$

where $Q_{a}$-accumulated heat flow which increases internal temperature in the bus $\theta_{s}, \mathrm{~W}$;

$Q_{v}$ - heat flow to ambient air, W.

Bus heating dynamics equations: 


$$
\begin{gathered}
Q_{a}=c \cdot m \frac{d \tau}{d t}, \\
Q_{v}=\alpha \cdot S \cdot \tau, \\
c \cdot m \frac{d \tau}{d t}+\alpha \cdot S \cdot \tau=P,
\end{gathered}
$$

where $c$ - specific heat capacity of the inside air, bus components and housing inside, $\mathrm{J} \cdot\left(\mathrm{kg} \cdot{ }^{\circ} \mathrm{C}\right)^{-1}$;

$m$ - mass of heated components $\mathrm{kg}$;

$\alpha$ - heat transfer coefficient from the bus surface to environment, $\mathrm{W} \cdot\left(\mathrm{m} 2 \cdot{ }^{\circ} \mathrm{C}\right)^{-1}$;

$S$ - surface area of the bus, $\mathrm{m}^{2}$;

$\tau=\left(\theta-\theta_{0}\right)-$ overtemperature $\left(\theta_{0}-\right.$ initial temperature of ambient air), ${ }^{\circ} \mathrm{C}$.

When expressing the heat flow equation in the differential form, the original heating element equation shall be obtained:

$$
T \frac{d \tau}{d t}+\tau=K_{p} \cdot P
$$

where $T$ - heating time constant of the bus, min;

$K_{p}$ - static transfer coefficient or gain for heating power, ${ }^{\circ} \mathrm{C} \cdot \mathrm{W}^{-1}$.

By using Laplace transformation, the operator equation is obtained and the transfer function is expressed:

$$
\begin{gathered}
T \cdot \tau(s) \cdot s+\tau(s)=K_{p} \cdot P(s), \\
W_{p}(s)=\frac{\tau(s)}{p(s)}=\frac{K_{p}}{T \cdot s+1},
\end{gathered}
$$

where $\tau(s)$ - reflection of overtemperature;

$P(s)$ - reflection of heating power.

The analytical calculation of these two parameters that describe the transmission function is very complicated, so an experimental study was carried out to determine $T$ and $K_{p}$.

\section{Experimental investigation object and methods}

To obtain the heating time constant $T$ that impacts the heating and cooling process dynamics and the static transfer coefficient or gain for the heating power $K_{p}$, the experimental investigations of the electrical minibus were performed. The electrical heater was installed in the bus passenger compartment and 8 temperature loggers were situated in different places of the compartment. Simultaneously the outside air temperature was measured. The placement of the heater and temperature measuring devices is shown in Figure 1.

The main characteristics of the investigated electric minibus:

- dimensions, mm: 7578x1993x2815;

- interior headroom, mm: 1820 ;

- passenger seats: 18

- electric motor continuous/peak power, $\mathrm{kW} ; 70 / 160$;

- range, $\mathrm{km}, 70$;

- battery capacity, kWh: 44 .

The power consumption of the electrical heater also was measured. There were performed several measurement cycles.

For temperature measuring 7 two-channel data logers HOBO $\mathrm{H} 8$ were used. Temperature range -3 to $+50{ }^{\circ} \mathrm{C}$, resolution $0.1{ }^{\circ} \mathrm{C}$ (in range 0 to $+40{ }^{\circ} \mathrm{C}$ ), accuracy $0.4{ }^{\circ} \mathrm{C}$ (in range -10 to $+50{ }^{\circ} \mathrm{C}$ ). For the measured temperatures, the accuracy is satisfactory enough, because within the measurement range it forms approximately only $3 \%$ error. 


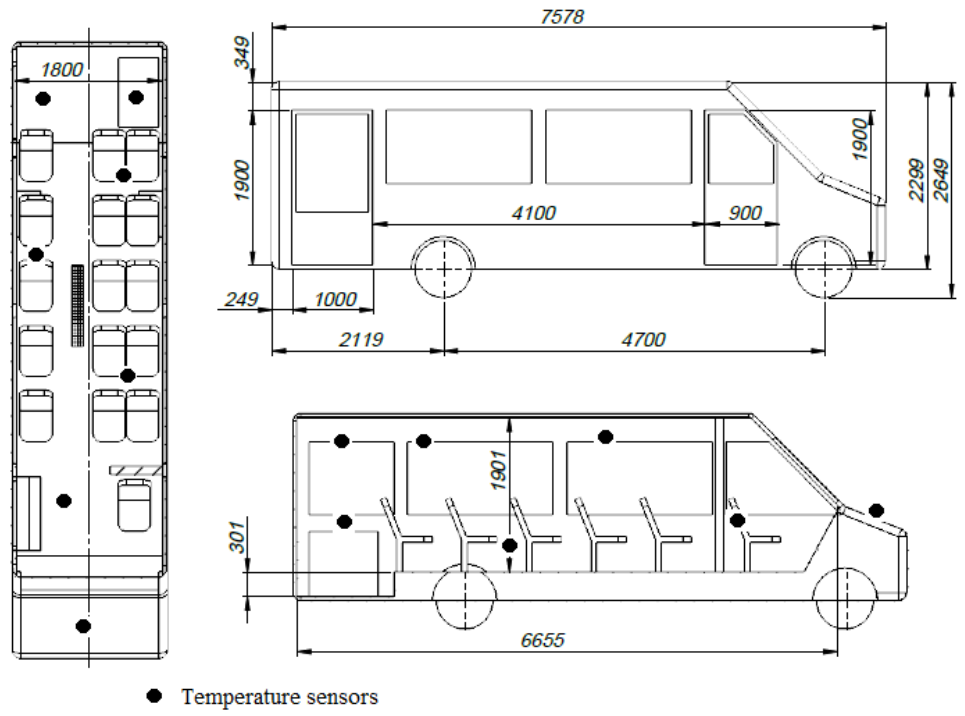

Fig. 1. Location of temperature sensors in electric minibus

The measurements were performed during temperature rise in the non-stationary process until the onset of the stationary process - the internal temperature does not change, as well as the cooling temperature decreases in the non-stationary process until the onset of the stationary process - reaching the outdoor air temperature.

\section{Results and discussion}

Experimental measurements were performed several times in a stationary located bus. Figure 2 shows the heating and cooling graphic representation in time. The temperature inside the bus was calculated as the average temperature of all sensors located near the ceiling of the bus.

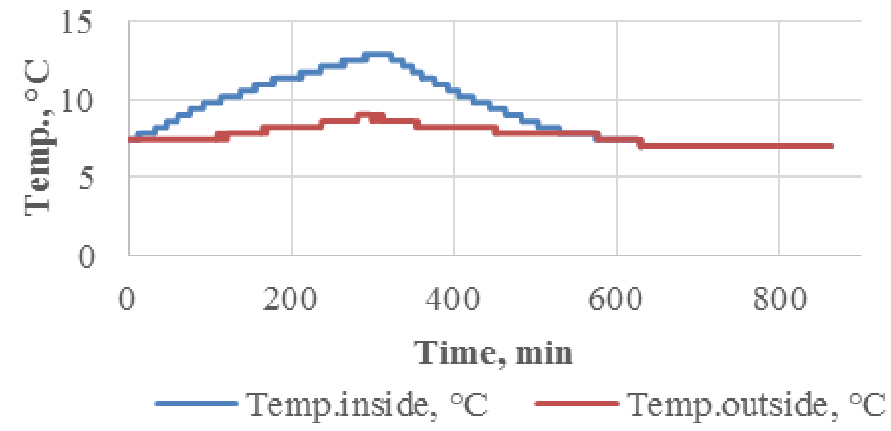

Fig. 2. Bus inside temperature changes during heating and cooling

The cooling curve shown in Figure 3 has been processed separately to find the bus heating/cooling time constant $T$. The heat transfer equilibrium must be developed using the overtemperature of the bus passenger compartment - the difference between the inside and outside temperatures.

The cooling curve was developed after switching off the electric heater and leaving the bus untouched to get the next stationary regime - when the inside temperature of the compartment drops to the level of the outside temperature - no heat transfer to any direction takes place.

To get the time constant $T$, it is necessary to obtain the descriptive equation for the overtemperature from the data obtained. The cooling curve is exponential:

$$
\tau(s)=\tau \cdot e^{-t / T} .
$$

Experimental data processing shows that the time constant or inertia criteria $T=115$ minutes (the stationary overtemperature is $6.1{ }^{\circ} \mathrm{C}, 63 \%$ of this value is $3.8{ }^{\circ} \mathrm{C}$ and it was reached after 115 minutes 
of heating). When combining the experimental and descriptive function data, the following curves in Figure 4 were obtained.

It is possible to find the static transfer coefficient or gain $K_{p}$ for heating power from the heating curve. Heating curves were obtained by heating with two electrical heaters (at first $P_{1}=1.9 \mathrm{~kW}$ and then $P_{2}=1.6 \mathrm{~kW}$ ). Such low power was chosen, because it reduces the impact of the different elements to the thermal inertia for data measuring. But it is possible to generalize the obtained data and calculate temperatures and the heating time using different heating power.

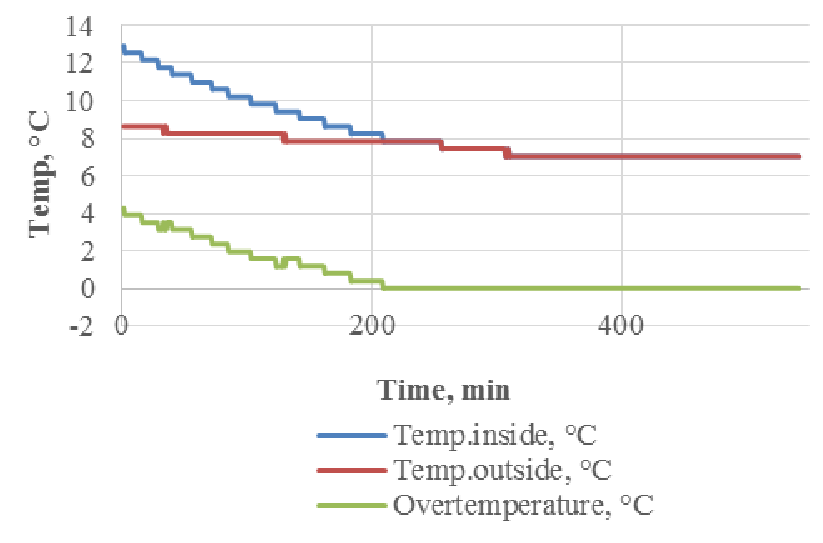

Fig. 3. Changes of bus inside air overtemperature $\tau$ during cooling

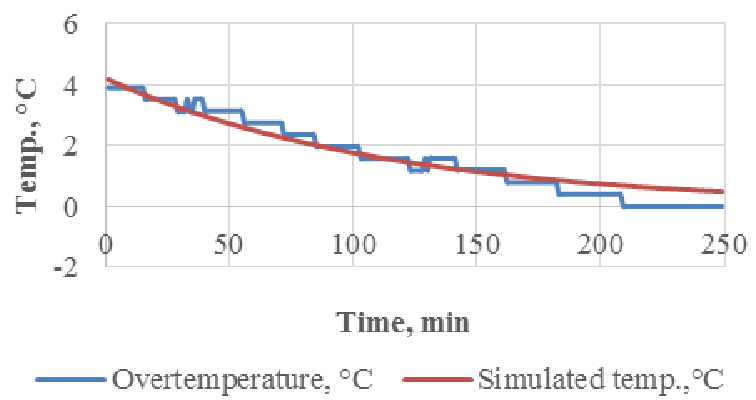

Fig. 4. Experimental and descriptive (analytic) function curves (time in minutes)

Reading the temperature values from the data obtained during both heating processes at time $t=T=115$, min $t_{1}=4.4{ }^{\circ} \mathrm{C}$ and $t_{2}=3.8^{\circ} \mathrm{C}$ was obtained. The static transmission factor by capacity $K_{p}{ }^{\circ} \mathrm{C} \cdot \mathrm{kW}^{-1}$ was found using the formula:

$$
K_{p}=\frac{t_{1}-t_{2}}{P_{1}-P_{2}}
$$

For the investigated minibus the static transmission factor by heating power is then $K_{p}=2.0^{\circ} \mathrm{C} \cdot \mathrm{kW}^{-1}$.

Using the obtained parameters, the transmission function is the following:

$$
W_{p}(s)=\frac{1.275}{115 \cdot s+1} .
$$

Using the conceived integrated model and inserting the values into formula (8), it is possible to find the overtemperature at any heating power:

$$
\tau(t)=2.0 \cdot P\left(1-e^{-t / 115}\right) .
$$

The developed model shows that even the small minibus microclimate system has to have substantial output energy in order to create appropriate comfort level for the passengers. The bus used for the experiments needs almost two hours to get to $2 / 3$ of the stated temperature (compartment 
saloon inertia is 115 minutes), and in order to increase the compartment temperature over the outside temperature by just $2.0^{\circ} \mathrm{C}$, it is necessary to have a heater with $1 \mathrm{~kW}$ heat output.

The correlation shows that the descriptive formula, with both coefficients, the bus sensitivity to heat supply or gain $(k)$ and inertia $(\tau)$, as well as the power as part of the energy flow, well corresponds to real situation in terms of temperature within the bus. These ratios will also be tested at other temperatures, but the current experiments show that they do not change and well describe the changes in the overtemperature inside the bus.

The research results and the analytic expressions developed will be used for further research to develop the autonomous heating system for the electric bus microclimate system.

\section{Conclusions}

1. The bus compartment has substantial heating inertia - the experiments show that a small bus with 18 seats has inertia of 115 minutes.

2. The heating system development challenge for the bus passenger compartment also is rather small gain over the heat energy input to the heater - it is just $2.0^{\circ} \mathrm{C}$ per $1 \mathrm{~kW}$. This means that in order to keep the bus passenger compartment temperature at the comfort level, there is a need for high power heat energy devices to be used.

3. The analytic temperature and energy expressions developed are having high reliability and are validated against the real bus temperature dynamics, and will be used for further research.

4. Investigations are carried out on a rebuilt cargo bus to passenger minibus, together with the firm that performed this rebuilding. The generalization of the results helps calculate the required capacity for the heating system to reach comfort temperatures in the rebuilt minibus at different outdoor temperatures.

5. The results indicated the need for the additional thermal insulation for the given minibus, and that is important to reduce the energy consumption for the passenger compartment heating.

\section{Acknowledgements}

This work has been supported by the European Regional Development Fund within the Project "Development of a Sustainable Heating Solution for the Salon of the Public Electric Transport", project identification number 1.1.1.1/18/A/168.

\section{References}

[1] In-Soo S., Minyoung L., Jedok ., Sang T. O., Jong-Phil W. Design and experimental analysis of an efficient HVAC (heating, ventilation, air-conditioning) system on an electric bus with dynamic on-road wireless charging. Energy, vol.81. March 2015, pp. 262-273.

[2] Velt K.B., Daanen H.A.M. Optimal bus temperature for thermal comfort during a cool day. Applied Ergonomics. Vol.62. July 2017, pp.72-76.

[3] Göhlich D., Fay T., Jefferies D., Lauth E., Kunith A., Zhang X. Design of urban electric bus systems. Design Science, Cambridge University Press: August 2018. Volume 4.

[4] Riachi Y., Clodic D. A numerical model for simulating thermal comfort prediction in public transportation buses. International Journal of Environmental Protection and Policy 2014; 2(1): January 30, 2014.

[5] Nilsson H., Holmér I. Comfort diagrams for improved evaluation of indoor climate. The Climate Group, The National Institute for Working Life, Sweden, SE-171 84 Solna, Sweden, Proceedings of the Fourth International Meeting on Thermal Manikins, EMPA Switzerland, 27-28 sept.2001.

[6] Basile R. Challenges for air conditioning and heating solutions in electrobuses. [Electronic resourse]. www.busworld.org/uploads/exhibitors_releases/143/06-HVAC-in-e-buses.pdf [viewed: 10.12.2019].

[7] Pathak A., Binder M., Chang F.i, Ongel A. Analysis of the influence of air curtain on reducing the heat infiltration and costs in urban electric buses. International Journal of Automotive Technology. Vol. 21, No. 1, January 2020. pp. 147-157. 